\title{
Design, fabrication and test of integrated micro-scale vibration-based electromagnetic generator
}

\author{
Santosh Kulkarni ${ }^{\mathrm{a}, *}$, Elena Koukharenko ${ }^{\mathrm{b}}$, Russell Torah ${ }^{\mathrm{b}}$, John Tudor ${ }^{\mathrm{b}}$, \\ Steve Beeby ${ }^{\mathrm{b}}$, Terence O'Donnell ${ }^{\mathrm{a}}$, Saibal Roy ${ }^{\mathrm{a}}$ \\ a Tyndall National Institute, Cork, Ireland \\ ${ }^{\mathrm{b}}$ University of Southampton, Southampton, UK
}

Received 29 June 2007; received in revised form 27 August 2007; accepted 17 September 2007 Available online 29 September 2007

\begin{abstract}
This paper discusses the design, fabrication and testing of electromagnetic microgenerators. Three different designs of power generators are partially micro-fabricated and assembled. Prototype A having a wire-wound copper coil, Prototype B, an electrodeposited copper coil both on a deep reactive ion etched (DRIE) silicon beam and paddle. Prototype $\mathrm{C}$ uses moving NdFeB magnets in between two micro-fabricated coils. The integrated coil, paddle and beam were fabricated using standard micro-electro-mechanical systems (MEMS) processing techniques. For Prototype A, the maximum measured power output was $148 \mathrm{nW}$ at $8.08 \mathrm{kHz}$ resonant frequency and $3.9 \mathrm{~m} / \mathrm{s}^{2}$ acceleration. For Prototype B, the microgenerator gave a maximum load power of $23 \mathrm{nW}$ for an acceleration of $9.8 \mathrm{~m} / \mathrm{s}^{2}$, at a resonant frequency of $9.83 \mathrm{kHz}$. This is a substantial improvement in power generated over other micro-fabricated silicon-based generators reported in literature. This generator has a volume of $0.1 \mathrm{~cm}^{3}$ which is lowest of all the silicon-based micro-fabricated electromagnetic power generators reported. To verify the potential of integrated coils in electromagnetic generators, Prototype $\mathrm{C}$ was assembled. This generated a maximum load power of $586 \mathrm{nW}$ across $110 \Omega$ load at $60 \mathrm{~Hz}$ for an acceleration of $8.829 \mathrm{~m} / \mathrm{s}^{2}$.

(C) 2007 Elsevier B.V. All rights reserved.
\end{abstract}

Keywords: Energy harvesting from vibrations; Micro-fabricated electromagnetic power generator; MEMS fabrication techniques; Testing of power generator

\section{Introduction}

Recently, energy harvesting has emerged as a solution for powering autonomous sensor nodes to increase their expected lifetimes. In wireless sensor applications where photovoltaic, optical, thermal, or electrical energy sources are not practical or available, energy harvesting devices that convert kinetic energy into electrical energy have attracted much interest. A variety of micro-machined vibration driven generators using electromagnetic principles to convert the kinetic energy of a suspended mass into electrical energy, are being studied for powering wireless sensor nodes. With the decreasing size and power requirements of wireless sensor networks, there exists a significant driver to miniaturize the size of the power generators.

Beeby et al. [1] have made a detailed review of the state of the art of vibration powered generators. Here, we briefly review

\footnotetext{
* Corresponding author. Tel.: +353214904441.

E-mail address: santosh.kulkarni@tyndall.ie (S. Kulkarni).
}

the main results relating to electromagnetic devices. In their recent work, Beeby et al. [2], present working of a small (volume $-0.1 \mathrm{~cm}^{3}$ ) electromagnetic generator using moving $\mathrm{NdFeB}$ magnets on beryllium-copper beam, placed around a fixed wirewound coil. They report a maximum power of $46 \mu \mathrm{W}$ from the device in a $4 \mathrm{k} \Omega$ load from $0.59 \mathrm{~m} / \mathrm{s}^{2}$ acceleration at a resonant frequency of $52 \mathrm{~Hz}$. Previously, El Hami et al. [3] presented results from an electromagnetic power generator comprising of cantilever beam with a pair of $\mathrm{NdFeB}$ magnets with wire-wound coil fixed between the poles of the magnets. They reported $1 \mathrm{~mW}$ of power generated for a $0.24 \mathrm{~cm}^{3}$ volume at a frequency of $320 \mathrm{~Hz}$. Further, Glynne-Jones et al. [4] demonstrated working of an assembled electromagnetic power generator, using fixed bulk magnets and moving wire-wound coil fixed on a stainless steel beam. The generator produced a power of $180 \mu \mathrm{W}$ at a frequency of $322 \mathrm{~Hz}$, acceleration of $2.7 \mathrm{~m} / \mathrm{s}^{2}$ and had a volume of $0.84 \mathrm{~cm}^{3}$. In recent work, Serre et al. [5] used a moving $\mathrm{NdFeB}$ magnet on a polyamide film and a fixed planar coil made of aluminum layer. The device produced a power of $200 \mathrm{nW}$ at a resonant frequency of $360 \mathrm{~Hz}$ for a displacement of $6.8 \mu \mathrm{m}$. 
In other work, Mizuno et al. [6] described the use of an integrated coil on a cantilever beam with fixed NdFeB magnets. They predicted a maximum power of $0.4 \mathrm{nW}$ for a volume of $2.1 \mathrm{~cm}^{3}$ at a frequency of $700 \mathrm{~Hz}$ and acceleration of $12.4 \mathrm{~m} / \mathrm{s}^{2}$. A silicon-based generator was reported by Kulah and Najafi [7], comprising of two separated chips combined together. They reported a maximum power of $4 \mathrm{nW}$ at $25 \mathrm{~Hz}$ frequency and volume of $2 \mathrm{~cm}^{3}$. The review by Beeby et al. [1] shows that there are no reported fully micro-fabricated (i.e., micro-fabricated coils, magnets, beam and housing) electromagnetic vibration generators to-date. The silicon-based micro-fabricated generators have low coil turns compared to the discretely assembled generators. Hence, a lower generated voltage and power when compared to discretely assembled devices. In order to compensate for low coil turns, we designed the generator to work at high frequencies. Here, the power generators were designed to work at input resonant frequency of $7400 \mathrm{~Hz}$ and acceleration of $1.1 \mathrm{~m} / \mathrm{s}^{2}$. These values were measured in commonly used industrial fan. In this case, vibrations are induced from rotating parts that may be improperly balanced. In our previous works [8], we have reported the design, simulation and assembly process of a microgenerator using integrated coils on silicon with $\mathrm{NdFeB}$ bulk magnets. For further integration, cost reduction and batch fabrication of the electromagnetic generator [9], we have reported the simulation results for a generator using integrated coils and electroplated CoPt micro-magnets. In our recent work, we suggest a novel method of developing nanostructured, stress-free and thick Co-rich CoPtP films using a combination of pulse-reverse plating and addition of stress relieving additives [10].

In this paper, we report further on a micro-scale vibration powered generator fabricated with an integrated $\mathrm{Cu}$-coil (electroplated) on silicon and bulk $\mathrm{NdFeB}$ magnets. We discuss the design, fabrication and assembly of three different electromagnetic generators. Prototypes A and B use wire-wound and electroplated coils, respectively, on a DRIE etched silicon paddle. The coils are placed between two sets of oppositely polarized $\mathrm{NdFeB}$ magnets. The volume of both the devices was around $106 \mathrm{~mm}^{3}$. It was observed that Prototypes A and B generated lower power output than expected. This was due to large parasitic damping in the silicon beam which reduced the amplitude of vibration leading to low power output. In order to verify the functioning of the integrated coils in the power generator a new design, Prototype $\mathrm{C}$, comprising of fixed integrated coil on silicon and two oppositely polarized $\mathrm{NdFeB}$ magnets placed above and below a beryllium-copper beam was assembled. This design had a lower parasitic damping, allowing the beryllium-copper beam and the magnets to vibrate with higher amplitudes. This device has a component volume of $150 \mathrm{~mm}^{3}$. Here, we compare the performance and characteristics of the three different power generators.

\section{Fabrication and assembly process}

The electromagnetic power generators work on the principle of electromagnetic induction. According to Faraday's law any time change in the magnetic field linking a coil will cause a voltage to be induced in the coil. The change could be produced

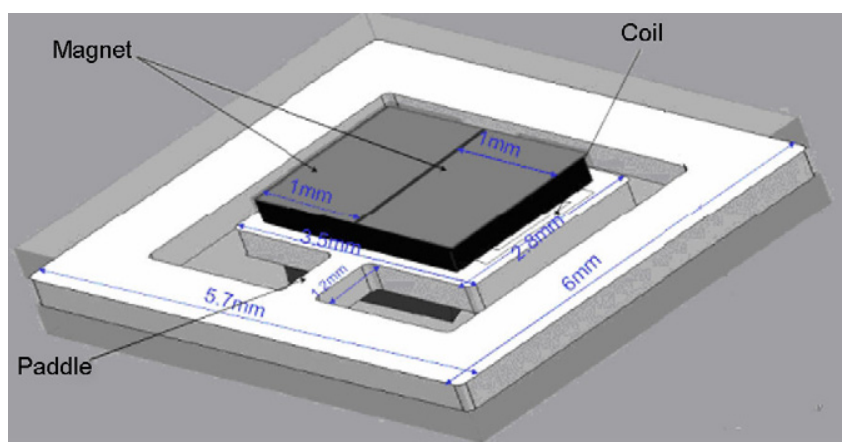

Fig. 1. Schematic electromagnetic power generator-Prototype A \& B.

either by moving the magnet, while keeping the coil fixed or vice versa. In this work, Prototypes A and B have fixed magnets with moving coils, while Prototype $\mathrm{C}$ uses fixed coils and moving magnets. The design, modeling and simulation details of the Prototypes A \& B have been reported previously [8]. Fig. 1 shows the schematic of the assembled power generator for Prototypes A \& B.

In this work, we use wire-wound $\mathrm{Cu}$ coils, thereby realizing a partially batch-fabricated version (Prototype A) and electroplated $\mathrm{Cu}$ coils, as a fully batch fabricated version (Prototype B). In both cases the coils are placed on a DRIE etched vibrating silicon paddle. Both devices use a soft magnetic steel plate over the hard magnets to concentrate the flux lines. In our previous work [9], we have shown that the output power generated can be improved by using a soft magnetic layer to concentrate the flux lines in the region between the magnets. Prototype $\mathrm{C}$ comprises sintered $\mathrm{NdFeB}$ magnets and beryllium-copper beam with integrated coils fabricated through standard MEMS processing techniques. Fig. 2 shows the schematic for Prototype C. For the three devices, the arrangement of magnets with the coils is such that each magnet covers half of the coils. The advantage of this arrangement is to maximize the flux gradient by vibrating the coils from a region of positive flux to negative flux. Fabrication details of Prototype A have been described previously [11].

Prototype A \& B, use a moving silicon paddle with $\mathrm{Cu}$ coils in a magnetic field for power generation. Four-inch silicon wafers with high resistivity $(17-33 \Omega \mathrm{cm})$ were etched by a DRIE process to fabricate the silicon paddle, frame and beam. Here, we spin and pattern a $20 \mu \mathrm{m}$ thick SPR220 resist and DRIE etch

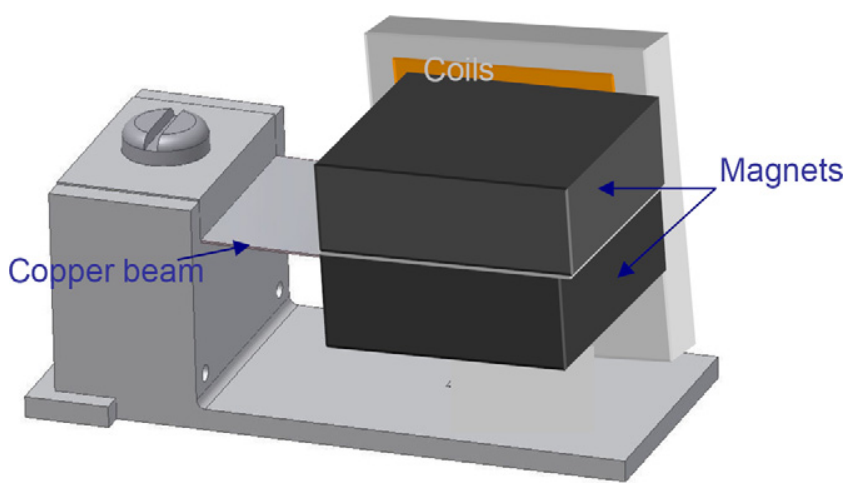

Fig. 2. Schematic of electromagnetic power generator Prototype C. 


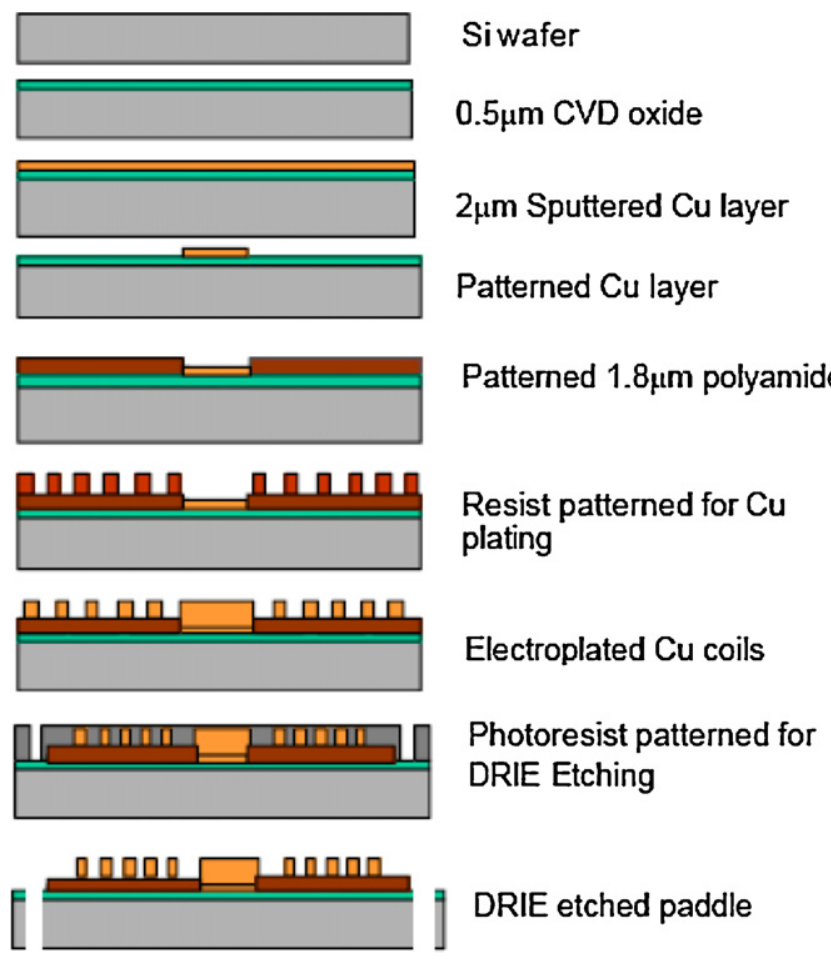

Fig. 3. Overview of process steps for integrated coil fabrication.

the silicon through the wafer. As a first test of the mechanical strength, the paddle and beam were tested using a standard weight set gradually added to a thin wire attached across the paddle. The weight was increased until the silicon structure broke. This simple test showed that the silicon beam could withstand 2.8-3 $\mathrm{N}$ applied force without and 4.5-5.5 $\mathrm{N}$ after chemical polishing.

Prototype A uses a conventionally wound coils with 600 turns, of $25 \mu \mathrm{m}$ diameter enameled copper wire recessed in a silicon cantilever paddle. The coil internal diameter is $0.5 \mathrm{~mm}$, external diameter is $2.4 \mathrm{~mm}$ and a thickness is $0.5 \mathrm{~mm}$. The measured resistance of the coil was $112 \Omega$. The resulting mass of the silicon paddle plus coil was $0.028 \mathrm{~g}$. In Prototype B, the wirewound copper coil is replaced by an electroplated copper coil. The basic electroplated coil design is a square, spiral structure with a $150 \mu \mathrm{m}$ contact pad in the centre. The coils have a track width and track space of $10 \mu \mathrm{m}$ with 65 turns and a coil resis-

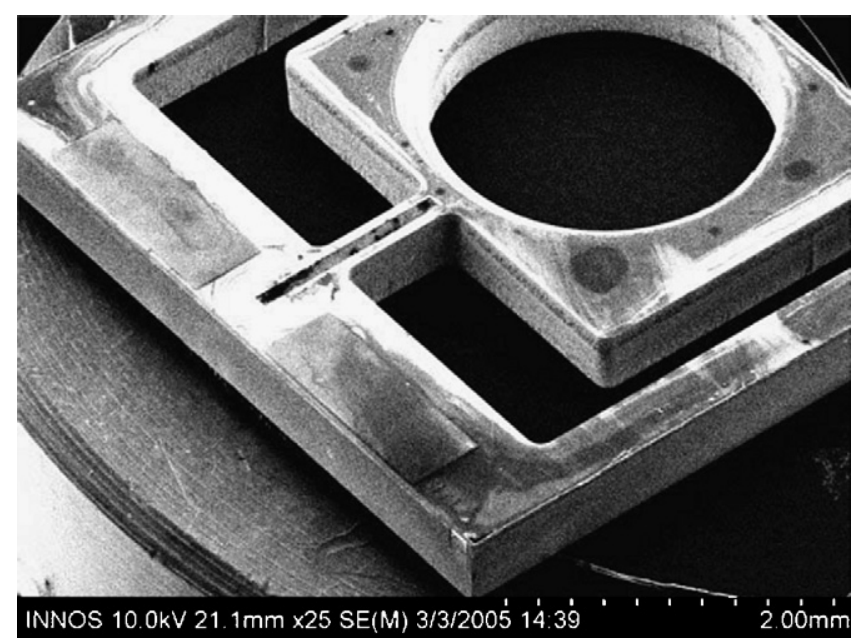

Fig. 5. DRIE etched silicon paddle will a recess for wirewound coil (Prototype A).

tance of $55 \Omega$. The $10 \mu \mathrm{m}$ thick copper coils are electrodeposited on top of an insulated $2 \mu \mathrm{m}$ thick bottom copper layer, which is sputtered on a silicon paddle $(3.5 \mathrm{~mm} \times 2.8 \mathrm{~mm} \times 0.5 \mathrm{~mm})$. The paddle is etched by DRIE and batch fabricated on a silicon wafer. A silicon cantilever beam $(0.3 \mathrm{~mm} \times 1.2 \mathrm{~mm} \times 0.5 \mathrm{~mm})$ connects the paddle to the frame. The mass of the silicon paddle with coil was $0.014 \mathrm{~g}$. Fig. 3 shows the process steps involved in the fabrication of an integrated coil on a DRIE etched paddle. Fig. 4 shows the resulting electrodeposited coil structure on a DRIE etched silicon paddle.

For final assembly of Prototype A \& B, the integrated coil (wire-wound and electroplated coils on silicon) is bonded between two sets of oppositely polarized $\mathrm{NdFeB}$ magnets, assembled in a Perspex chip. For the magnet assembly, Perspex chips $(6 \mathrm{~mm} \times 6 \mathrm{~mm} \times 3 \mathrm{~mm})$ are fabricated using traditional milling techniques. Each chip has a $(2 \mathrm{~mm} \times 2 \mathrm{~mm} \times 2 \mathrm{~mm})$ cavity etched in the middle. A steel plate $(2 \mathrm{~mm} \times 1 \mathrm{~mm} \times 1 \mathrm{~mm})$ is glued in the Perspex etched slot, over which two oppositely polarized $\mathrm{NdFeB}$ magnets $(1 \mathrm{~mm} \times 2 \mathrm{~mm} \times 1 \mathrm{~mm})$ are bonded. Two such Perspex chips containing the magnets are individually glued on the silicon chip with DRIE etched paddle. During assembly, the three chips are placed such that the magnets are aligned over center of the coil. Fig. 5 shows the SEM image of a DRIE etched silicon paddle with a recess for wire-wound

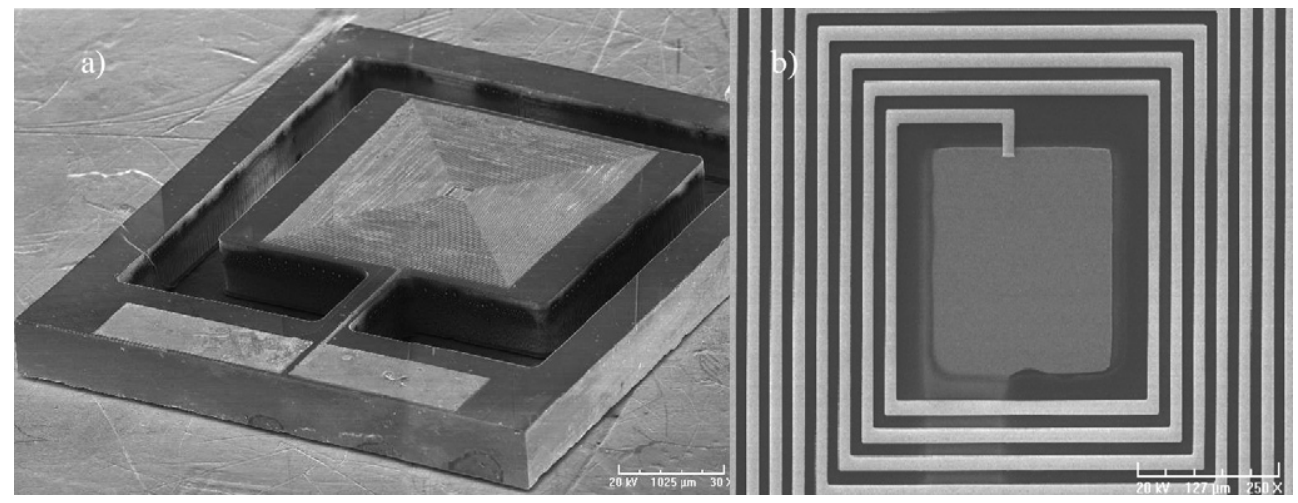

Fig. 4. SEM image of (a) integrated coil structure with DRIE etched paddle and (b) electroplated copper coil structure. 


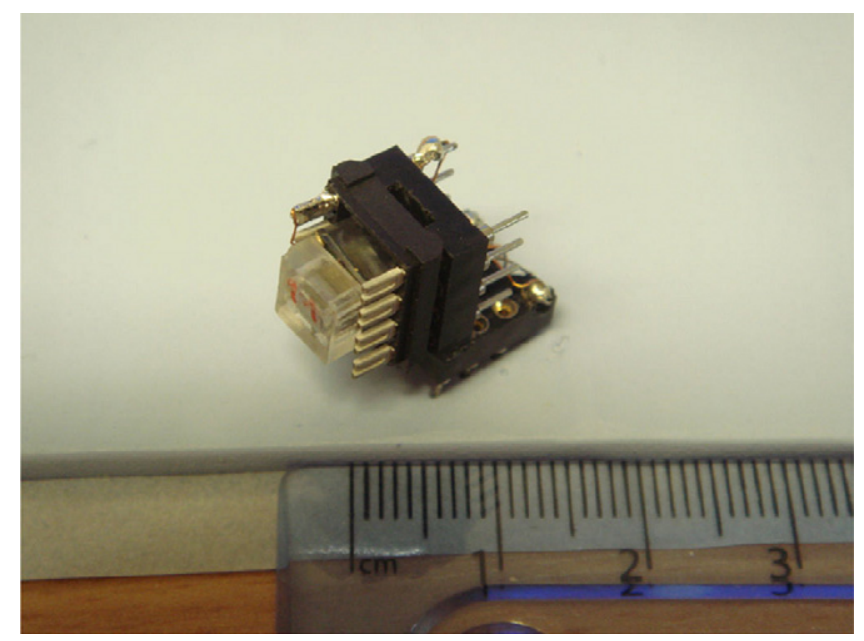

Fig. 6. Assembled silicon generator, Prototype A \& B with discrete magnets and integrated coils.

coil (Prototype A). The assembled microgenerator with discrete magnets and integrated coil is shown in Fig. 6.

Prototype $\mathrm{C}$ uses two bulk $\mathrm{NdFeB}$ magnets $(3 \mathrm{~mm} \times 1 \mathrm{~mm} \times 1.5 \mathrm{~mm})$. One magnet is placed above and the other with opposite polarity, below a beryllium/copper beam, which is $9 \mathrm{~mm}$ long, $3 \mathrm{~mm}$ wide and $55 \mu \mathrm{m}$ thick. The cantilever beam assembly was clamped onto the base using an M1 sized nut, bolt and a washer. The mass of the beam with the magnets was $0.54 \mathrm{~g}$. Two of the above electroplated $\mathrm{Cu}$ coils on silicon were fixed on either side of the magnets and the beam. The number of turns in a single coil was 65 and coil resistance of each integrated coil was measured to be $55 \Omega$. Hence, the total coil resistance for the set-up (two integrated coils) was measured as $110 \Omega\left(R_{\text {coil }}=110 \Omega\right)$. The coils were placed with the center of the coil aligned to the beam and the outer diameter of the coil covered by the magnets, this to maximize the flux gradient of the coils. The gap between the coils and magnets was about $0.5 \mathrm{~mm}$. On application of external vibrations, the beam with oppositely polarized magnets resonates vertically between the integrated coils. The motion of the magnets leads to a change in the flux linking the coils and this leads to generation of voltage. Thus, converting the vibrational energy of the magnets into electrical energy across the coils.

\section{Results and discussion}

For measurement of generator output power, the two Prototypes were tested using a Bruel \& Kjaer 4810 mini shaker driven from a signal generator through a power amplifier. The excitation vibrations were measured using a Piezotronics (model 354C03) three-axis accelerometer. The tests were performed at acceleration levels of $3.924 \mathrm{~m} / \mathrm{s}^{2}$ for Prototype A and $9.81-39.24 \mathrm{~m} / \mathrm{s}^{2}$ for Prototype B device. The resonant frequencies of the two generators were measured on a Hewlett Packard 3588 A $10 \mathrm{~Hz}$ to $150 \mathrm{MHz}$ spectrum analyzer. The generator output was applied across an impedance matched load and the voltage was observed on a digital oscilloscope. The quality factor for the device is calculated as the ratio of resonant frequency at open load condition (a)

Power output versus frequency

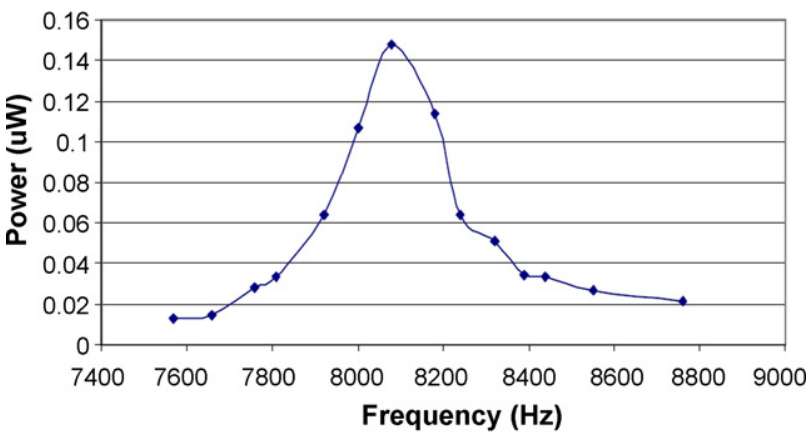

(b)

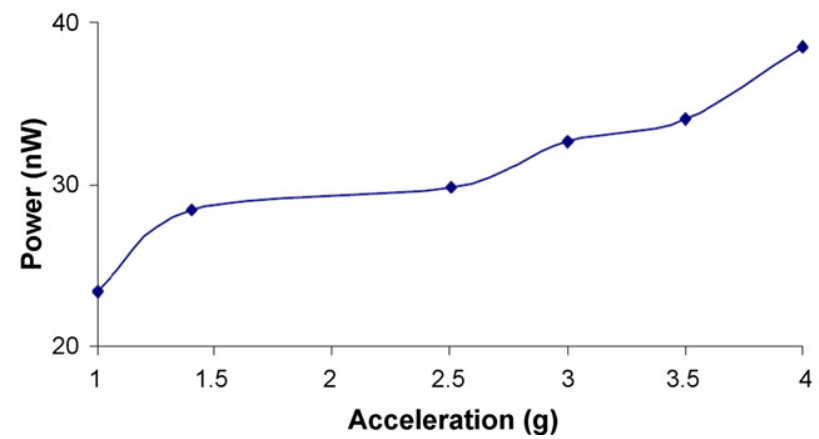

Fig. 7. (a) Variation of load power vs. frequency for Prototype A and (b) variation of load power vs. acceleration for Prototype B.

and difference in frequencies at half the power at resonant frequency. The value of parasitic damping $\left(\xi_{\mathrm{T}}\right)$ is the reciprocal of quality factor $\left(Q_{\mathrm{T}}\right)$ at open load condition as in Eq. (1).

$Q_{\mathrm{T}}=\frac{1}{2 \xi_{\mathrm{T}}}$

The variation of power with frequency of Prototype A generator is presented in Fig. 7(a). The value of the maximum power was $148 \mathrm{nW}$ at $8.08 \mathrm{kHz}$ resonant frequency and $3.9 \mathrm{~m} / \mathrm{s}^{2}$ acceleration. The quality factor for the device was measured as 26. For Prototype B, the resonant frequency was observed at $9.837 \mathrm{kHz}$. The quality factor, Q, for the device was 164 . The power extracted from the device was about $23 \mathrm{nW}$ for an acceleration of $9.81 \mathrm{~m} / \mathrm{s}^{2}$ into a $52.7 \Omega$ load resistance. The output power was measured at different acceleration levels, up to $39 \mathrm{~m} / \mathrm{s}^{2}$, for the same load resistance. Fig. 7(b) shows the variation of output power with the acceleration levels. The maximum power output from the device was $40 \mathrm{nW}$ at acceleration of $39.24 \mathrm{~m} / \mathrm{s}^{2}$ for a load resistance of $52.7 \Omega$. The reason for the low output power from the device could be due to lower amplitude of the paddle and the beam. The low amplitude of vibration may be due to a high value of parasitic damping. For Prototype A, the high parasitic damping was due to the friction between the leads of the wire-wound coil and the Perspex lid. The high parasitic damping in case of Prototype B is under investigation.

As mentioned earlier the generators were designed to operate at $7400 \mathrm{~Hz}$ as measured in an industrial fan. In practice, the resonant frequency of the generators was $8.08 \mathrm{kHz}$ and $9.8 \mathrm{kHz}$. This increase in frequency over the design value was due to variations in the fabrication process which resulted in the dimensions of 
Table 1

Comparison between Prototypes A, B \& C

\begin{tabular}{|c|c|c|c|c|c|}
\hline Device & Mass $(\mathrm{g})$ & Frequency $(\mathrm{Hz})$ & Acceleration $\left(\mathrm{m} / \mathrm{s}^{2}\right)$ & Max. load power (nW) & Volume $\left(\mathrm{mm}^{3}\right)$ \\
\hline Prototype A & 0.028 & 8080 & 3.9 & 148 & 106 \\
\hline Prototype B & 0.014 & 9837 & 9.81 & 23 & 106 \\
\hline Prototype C & 0.54 & 60 & 8.829 & 584 & 150 \\
\hline
\end{tabular}

the fabricated devices being different from the design. However, as the values of parasitic damping in the silicon-based generators reported here are very high, we needed higher values of acceleration to vibrate the paddle and beam. For high values of parasitic damping, most of input energy is required to keep the paddle and beam vibrating; available energy for electrical power generation is not large enough to produce significant levels of power and voltage.

Hence, to verify the potential of electromagnetic power generator using integrated coils, Prototype $\mathrm{C}$ was assembled. As mentioned earlier, Serre et al. [5], have reported performance of similarly arranged generator, with moving magnets and fixed micro-fabricated coils. Their generator produced a maximum power of $200 \mathrm{nW}$ at $360 \mathrm{~Hz}$ for a vibrational displacement of $6.8 \mu \mathrm{m}$. In case of Prototype $\mathrm{C}$, the resonant frequency was found to be around $60 \mathrm{~Hz}$. Fig. 8 shows the variation of load voltage (peak-peak) and load power with load resistance. Here, the acceleration was kept constant at $8.829 \mathrm{~m} / \mathrm{s}^{2}$. From Fig. 8, Prototype $\mathrm{C}$ generates a maximum power of $584 \mathrm{nW}$ and load voltage of $23.5 \mathrm{mV}$ (peak-peak) at a load resistance of $110 \Omega$ $\left(R_{\text {load }}=110 \Omega\right)$. At resonance and open load condition, the beam was estimated to move by a maximum displacement of $1.5 \mathrm{~mm}$. In this condition, the only damping present in the device is the parasitic damping, whose value can be calculated from the equation given below

$Z_{\max }=\frac{m a}{D 2 \pi f_{\text {res }}}$

where $m$ is the mass of the beam, $a$ the acceleration, $D$ the total damping (in this case parasitic damping) and $f_{\text {res }}$ is the resonant frequency. The value of parasitic damping is calculated to be $0.0084 \mathrm{~N} \mathrm{~s} / \mathrm{m}$. For an electromagnetic power generator, the optimum power condition is reached when the values of parasitic and electromagnetic damping are equal [12]. The electromagnetic

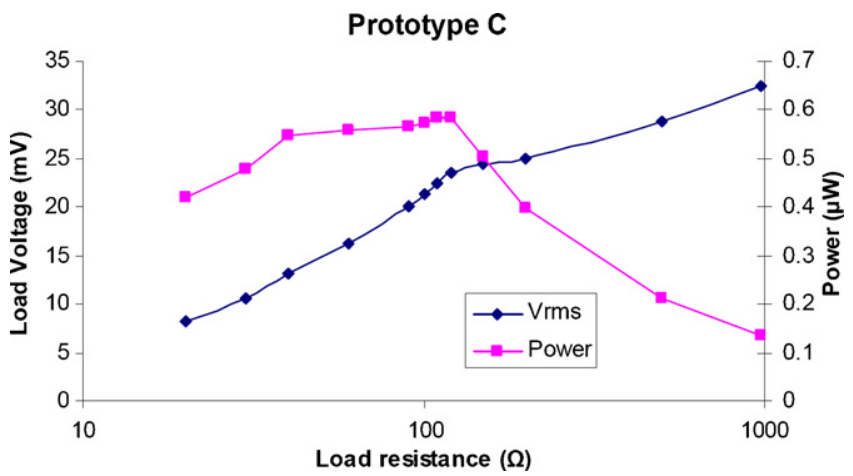

Fig. 8. Variation of load resistance with load voltage and load power for Prototype C. damping can be calculated from,

$D_{\mathrm{em}}(Z)=\left(\frac{\mathrm{d} \phi}{\mathrm{d} Z}\right)^{2} \frac{N^{2}}{R_{\text {coil }}+R_{\text {load }}}$

here $\mathrm{d} \phi / \mathrm{d} Z$ is the flux gradient and $N$ is the number of coil turns. The value of flux gradient per turn from finite element analysis is $1.063 \times 10^{-3} \mathrm{~Wb} / \mathrm{m}$. Using this in Eq. (3), the maximum electromagnetic damping per coil is $4.34 \times 10^{-5} \mathrm{~N} \mathrm{~s} / \mathrm{m}$ for $R_{\text {load }}=0 \Omega$. The value of electromagnetic damping decreases with increasing $R_{\text {load}}$, with other parameters remaining the same. In this case, as the value of electromagnetic damping is low compared to parasitic damping, the electromagnetic damping cannot be increased to equal the parasitic damping, to reach the optimum power condition. Here, the displacement given by Eq. (2) is determined by parasitic damping only. In this case, the load power is obtained from the voltage division between the coil and the load. Hence, maximum power is generated across the load, when the load and the coil resistance are equal [12]. This can be seen from Fig. 8, the maximum power of $586 \mathrm{nW}$ is transferred across load when the load resistance equals coil resistance $\left(R_{1}=R_{\mathrm{c}}=110 \Omega\right)$. Table 1 summarizes the experimental results from Prototype A, $\mathrm{B}$ and $\mathrm{C}$.

\section{Conclusion}

This paper describes the design, fabrication and the test results of three types of electromagnetic micropower generators on silicon. Prototype A uses a wire-wound coil placed in DRIE etched silicon paddle (partially batch-fabricated), Prototype B uses an electrodeposited $\mathrm{Cu}$ coils on silicon paddle (fully batch-fabricated). Prototype A and B generators were designed to operate at high frequencies to compensate for low coil turns. The test results of the devices have been reported, for Prototype A, the maximum power output measured was $148 \mathrm{nW}$ at $8.08 \mathrm{kHz}$ resonant frequency and $3.9 \mathrm{~m} / \mathrm{s}^{2}$ acceleration. Similarly, for Prototype B, the resonant frequency was measured at $9.84 \mathrm{kHz}$. At this frequency, the microgenerator gave a maximum load power of $23 \mathrm{nW}$ for acceleration of $9.8 \mathrm{~m} / \mathrm{s}^{2}$, at a load resistance of $52.7 \Omega$. This is a substantial improvement in power generated over other micro-fabricated silicon-based generators reported in literature. The generators have a volume of $0.1 \mathrm{~cm}^{3}$ which is the lowest of all silicon-based micro-fabricated electromagnetic power generators reported. Still the value of parasitic damping is too large in case of silicon-based generators. Hence, most of the input power is used in keeping the beam vibrating leaving a small portion for electrical power generation. The performance of electromagnetic power generators using integrated coil was improved using a different design. Prototype $\mathrm{C}$ has two oppositely polarized $\mathrm{NdFeB}$ on beryllium-copper 
beam placed between two electroplated copper coil on silicon. This generated a maximum power of $586 \mathrm{nW}$ measured across a $110 \Omega$ load resistance at a frequency of $60 \mathrm{~Hz}$ and acceleration of $8.829 \mathrm{~m} / \mathrm{s}^{2}$.

\section{Acknowledgement}

The authors would like to acknowledge the financial support by the European Union Framework 6 STREP project VIBES -No. 507911.

\section{References}

[1] S.P. Beeby, M.J. Tudor, N.M. White, Energy harvesting vibration sources for microsystems applications, Meas. Sci. Technol. 17 (2006) R175R195.

[2] S.P. Beeby, R.N. Torah, M.J. Tudor, P. Glynne-Jones, T. O'Donnell, C.R. Saha, S. Roy, Micro electromganetic generator for vibration energy harvesting, J. Micromech. Microeng. 17 (7) (2007) 1257-1265.

[3] M. El-Hami, P. Glynne-Jones, E. James, S.P. Beeby, N.M. White, A.D. Brown, J.N. Ross, M. Hill, Design and fabrication of new vibration of a new vibration-based electromechanical power generator, Sens. Actuators A 92 (2001) 335-342.

[4] P. Glynne-Jones, M.J. Tudor, S.P. Beeby, N.M. White, An electromagnetic, vibration-powered generator for intelligent sensor systems, Sens. Actuators A 110 (2004) 344-349.

[5] C. Serre, A. Perez Rodriquez, N. Fondevilla, J.R. Morante, J. Montserrat, J. Esteve, Vibrational energy scavenging with Si technology electromagnetic inertial microgenerators, Microsyst. Technol. 13 (11/12) (2007) $1655-1661$.

[6] M. Mizuno, D. Chetwynd, Investigation of a resonance microgenerator, J. Micromech. Microeng. 13 (2003) 209-216.

[7] H. Kulah, K. Najafi, An electromagnetic micro power generator for lowfrequency environmental vibrations, in: Proceedings of the 17th IEEE Conference on Micro-Electro Mechanical Systems (MEMS), Maastricht, 2004, pp. 237-240.

[8] S.P. Beeby, M.J. Tudor, E. Koukharenko, N.M. White, T. O'Donnell, C. Saha, S. Kulkarni, S. Roy, Micromachined silicon generator for harvesting power from vibrations, in: Proceedings of 4th International Workshop on Micro and Nanotechnology for Power Generation and Energy Conversion Application: Power MEMS, Kyoto, Japan, November 28-30, 2004.

[9] S. Kulkarni, S. Roy, T. O'Donnell, S. Beeby, J. Tudor, Vibration-based electromagnetic micropower generator, J. Appl. Phys. 99 (8) (2006) 08P511.

[10] S. Kulkarni, S. Roy, Development of nanostructured, stress-free Co-rich CoPtP films for magnetic microelectromechanical system applications, J. Appl. Phys. 101 (2007) 09K524.

[11] E. Koukharenko, S. Beeby, J. Tudor, N. White, T. O'Donnell, C. Saha, S. Kulakrni, S. Roy, MEMS vibration powered electromagnetic generator for wireless sensor applications, Microsyst. Technol. 12 (10/11) (2006) 1071-1077.

[12] C.R. Saha, T. Odonnell, H. Loder, S. Beeby, J. Tudor, Optimization of an electromagnetic energy harvesting device, IEEE Trans. Magn. 42 (10) (2006) 3509-3511

\section{Biographies}

Santosh Kulkarni did a B.Eng. in electronics \& communication at Karnatak University, India, in 2001. He has recieved MPhil in microelectronics eng. \& semiconductor physics from University of Cambridge, Cambridge, UK, in 2003. He is currently working for his $\mathrm{PhD}$ with Dr. Saibal Roy and Dr. Terence O'Donnell, in microelectronics at Tyndall National Institute, Cork, Ireland. He is working on the design, simulation and batch-fabrication of micropower generators using integrated coils and magnets. He is also working on development of thick, stress-free and nano-structured CoPtP films for MEMS applications. His research interests include design, fabrication and testing of MEMS and NEMS devices for different applications.

Dr. Elena Koukharenko received her engineering and technology degree from Chemical Technological University of Minsk (Republic of Belarus) in 1995. She obtained her Master Diploma in physical chemistry of condensed matter from the University of Montpellier II in 1996. Between 1997 and 2000 she jointly attended the Belarusian State University of Minsk and University of Montpellier II (France) for her $\mathrm{PhD}$ working on $\mathrm{Bi}-\mathrm{Sb}-\mathrm{Te}$ thin films for thermoelectric applications. Since 2001 she has been employed as a research fellow at the School of Electronics and Computer Science, Southampton University. Her interests include design, micro/nanofabrication of MEMS/NEMS sensors for different applications (inertial sensors, atom chip, power harvesting), and microstructural and physical properties characterisation of micro and nanostructures. She has 45 publications in the areas of thermoelectric materials and MEMS devices.

Russel Torah obtained his degree of B.Eng. (Hons) in electronics engineering in 1999 and an MSc in instrumentation and transducers in 2000 at the University of Southampton. After completing his $\mathrm{PhD}$ on optimisation of piezoelectric properties in thick film PZT ceramics, he was appointed as a research fellow within the electronics systems design group at the University of Southampton and has research interests in thick film technology and MEMS devices.

John Tudor obtained a BSc (Eng) in electronic and electrical engineering from University College London in 1983 and a PhD in Physics from Surrey University in 1988 . He is currently a principal research fellow in electronics and computer science at Southampton University. His research interests are microsystems, sensors and energy harvesting. He is a founder of the energy harvesting company Perpetuum (http://www.perpetuum.co.uk).

Dr. Steve Beeby is a reader in the School of Electronics and Computer Science (ECS) at the University of Southampton. He competed his PhD in 1997 after which he worked on an industrially funded research project developing micromachined silicon resonant sensors and an EPSRC funded research project investigating the combination of screen printed piezoelectric materials with micromachined silicon structures. This led to the award of a prestigious EPSRC Advanced Fellowship. He was the project co-ordinator of an EU Framework 6 STREP project 'Vibration Energy Scavenging (VIBES)' and is P.I. on a recently awarded EPSRC project entitled 'Otoacoustic Emission-Based Biometric Systems'. He is a co-founder of Perpetuum Ltd., a University spin-out based upon vibration energy harvesting and his energy scavenging research with Innos Ltd. and Perpetuum won the EuroAsia IC Industry award for R\&D Initiative of the year 2006. He has over 130 publications in the field, 5 patents and is co-author of a book entitled 'MEMS Mechanical Sensors' published by Artech House. He is a member of the EPSRC peer review College, reviewer for numerous journal publications, a Chartered Engineer and Chartered Physicist.

Terence O'Donnell received his BE in electrical engineering from University College, Dublin in 1991. In 1996 he received his PhD degree from University College Dublin for research in the area of finite element analysis of magnetic field problems. He is presently a senior research officer based in the Tyndall National Institute in Cork, where he is currently leading the research activity on integrated magnetics. He has worked on numerous research projects relating to design, modelling and fabrication of planar magnetics for power conversion and data communications, integrated RF inductors, magnetic field sensors, and magnetics for remote inductive powering. Current research interests include the design, modelling and fabrication of integrated magnetic components.

Dr. Saibal Roy is senior research scientist at Tyndall National Institute, Cork, Ireland. He did MS in physics and received his PhD in materials science in 1994. Since receiving his $\mathrm{PhD}$ he has 10 years university/institute and 3 years industrial research experience. Within University experiences he worked in IEM (Instituto fur estructura de la material), Madrid, Spain as post doctoral scientist; Phys. Dept., NTU (National Taiwan University), Taipei, Taiwan as visiting scientist; DIT (Dublin institute of technology), Dublin, Ireland as Arnold F. Graves fellow in solid state physics. Within Industrial experiences he worked DSL (Datar Switchgear Limited), Bombay, India as senior research scientist (Group head); ACC Limited \& PHILIPS, India as visiting scientist. Dr. Roy's research inter- 
ests at Tyndall include the preparation and characterization of nanostructured magnetic materials, nanotube/nanowire-polymer thermal interface materials and microelectronic fabrication processes. Presently he is supervising $4 \mathrm{PhD}$ students, 3 postdoctoral research associates. Dr. Roy was able to bring substantial
Government as well as corporate research funding. He is regular reviewer of different journal publications and invited in many university/research institutes and conferences as invited speaker. So far he has published 60 papers in esteemed journals and international conference proceedings. 